\title{
Glaucoma Awareness and Knowledge Among Ethiopians in a Tertiary Eye Care Center
}

\author{
Curtis J. Heisel · Cherinet M. Fashe · Philip S. Garza · Girum W. Gessesse • \\ Christine C. Nelson · Lemlem Tamrat · Rebhi Abuzaitoun • \\ Scott D. Lawrence
}

Received: September 2, 2020 / Accepted: October 8, 2020 / Published online: October 29, 2020

(C) The Author(s) 2020

\section{ABSTRACT}

Introduction: Glaucoma outcomes are closely associated with patients' awareness of the disease. However, little is known about glaucoma awareness and knowledge in Addis Ababa, a densely populated and ethnolinguistically diverse capital city in Ethiopia, the second largest country in Africa.

Methods: We performed a cross-sectional survey in the ophthalmology waiting room at St. Paul's Hospital, a tertiary care center in Addis Ababa. Respondents included patients, patient family members, and non-clinical staff. Participants were asked if they had read or heard about glaucoma to gauge basic awareness of the

Electronic supplementary material The online version of this article (https://doi.org/10.1007/s40123020-00314-1) contains supplementary material, which is available to authorized users.

\section{J. Heisel}

University of Michigan Medical School, Ann Arbor, MI, USA

C. M. Fashe - G. W. Gessesse - L. Tamrat .

S. D. Lawrence $(\bowtie)$

St. Paul's Hospital Millennium Medical College, Addis Ababa, Ethiopia

e-mail: scottlaw@med.umich.edu

P. S. Garza · C. C. Nelson · R. Abuzaitoun .

S. D. Lawrence

Department of Ophthalmology and Visual Sciences, University of Michigan Medical School, Ann Arbor, MI, USA disease; those with awareness were asked to take a quiz to measure their objective glaucoma knowledge. We performed multivariable regression to identify factors associated with glaucoma awareness, quiz performance, and self-rated ability to use eye drops.

Results: Of 298 respondents, 145 (48.7\%) were female, and the average age was $44.9 \pm 17.2$ years. A majority $(167 ; 56.0 \%)$ had primary school or less than primary school education. Only 131 (44.0\%) had basic glaucoma awareness. Of these, 95 (72.5\%) knew that glaucoma causes permanent vision loss, 103 (78.6\%) knew glaucoma is often asymptomatic in early stages, $62(47.3 \%)$ identified elevated intraocular pressure as a glaucoma risk factor, and 124 (94.7\%) knew glaucoma was treatable. A majority of this subset $(126 ; 96.2 \%)$ said they would be willing to use medicated eye drops, and 130 (99.2\%) indicated a willingness to undergo surgery if recommended. Education level was independently associated with glaucoma awareness $(p<0.001)$ and glaucoma quiz performance $(p=0.03)$.

Conclusion: In a population sample from an ophthalmology waiting room in Addis Ababa, glaucoma awareness was poor and most strongly associated with education level. Educational interventions at public health and provider-patient levels are warranted. Our results suggest high receptiveness to both medical and surgical treatment. 
Keywords: Awareness; Education; Ethiopia; Glaucoma; Knowledge

\section{Key Summary Points}

\section{Why carry out this study?}

Glaucoma represents a significant cause of preventable blindness in Ethiopia.

Increasing public awareness and understanding of glaucoma and its treatments could help alleviate this burden.

This study sought to assess the prevalence of glaucoma awareness and knowledge within an Ethiopian population. Through understanding the factors that influence glaucoma awareness and understanding, efforts to improve these metrics can be directed in an efficient manner.

\section{What was learned from the study?}

Awareness of glaucoma was found in just $44 \%$ of study participants, and just $28.2 \%$ of participants reported that their knowledge of glaucoma was good or very good.

A higher level of education was associated with both awareness of glaucoma and a higher score on an objective measure of glaucoma knowledge. A personal history of glaucoma was associated with a higher self-reported knowledge of glaucoma.

Future studies should further investigate reasons for low glaucoma awareness and interventions to increase awareness in this community.

\section{DIGITAL FEATURES}

This article is published with digital features, including a summary slide, to facilitate understanding of the article. To view digital features 
In 2007, a glaucoma consortium was established in Ethiopia with the intent of raising public awareness about the disease [7]. Through radio campaigns, TV advertisements, and community events, this group saw early results suggesting that awareness of glaucoma was spreading among Ethiopian communities. Despite these efforts, little information exists regarding the actual awareness of glaucoma within Ethiopia. Our study sought to assess the prevalence of glaucoma awareness, the degree of knowledge possessed by those who were aware of glaucoma, and the self-reported ability of those individuals to use eyedrops, the main first-line treatment for glaucoma. It was hypothesized that awareness of glaucoma and its associated treatments within the study population, a low- to middle-class subset of individuals seeking low-cost care at St. Paul's Hospital in Addis Ababa, would be relatively low.

\section{METHODS}

This clinic-based, cross-sectional observational study was approved by both the University of Michigan (HUM00148963) and St. Paul's Hospital Millennium Medical College (SPHMMC) Institutional Review Boards and was conducted in accordance with the tenets of the Declaration of Helsinki. All subjects provided informed consent to participate in the study. Data were collected between March-April 2019 in the ophthalmology clinic waiting room of SPHMMC in Addis Ababa, Ethiopia, a hospital with a catchment population of over 5 million people comprising all of Ethiopia's major ethnolinguistic groups. Participants consisted of patients of the clinic as well as non-patient family members and non-clinical staff. Persons $<18$ years of age, those who were not fluent in English, Amharic, or Afan Oromo, and those unable or unwilling to provide verbal informed consent were excluded. Because the research was conducted as a sub-study of a periocular anthropometrics study to be published separately, persons with a history of orbital disease were excluded. The informed consent script and survey questions were translated in real time from the original English documents by study staff who were fluent in English and Amharic and/or Afan Oromo (as appropriate for the patient's preferred language), and participants' responses were marked on paper data collection documents by study staff in real time.

We collected demographic information including age, sex, primary language, education level, profession, district ("woreda") of residence, and primary ethnicity (Amhara, Oromo, Gurage, Tigray, Silt'e, Gamo, or other). Participants with fewer than three grandparents of one ethnicity were recorded as mixed ethnicity. We asked participants if they had heard of or read anything about glaucoma to assess their basic awareness of the disease; those who answered negatively were not asked to answer additional questions about glaucoma. Of those participants who indicated an awareness of the disease, we asked where they had learned about glaucoma and if they knew they had glaucoma. Additionally, we asked these respondents to self-rate their knowledge of glaucoma and ability to successfully use medicated eye drops on a 5 -point Likert scale, where 1 represented very poor knowledge/ability and 5 represented very good knowledge/ability. Participants answered quiz questions in true-or-false and multiplechoice formats to assess their objective knowledge of glaucoma. They were then asked whether they would undergo surgery for glaucoma or use eye drops for as long as necessary to treat glaucoma if these interventions were recommended by a doctor. The complete screening checklist, informed consent checklist, and glaucoma survey are available in Online Appendix 1.

Analyses were performed with SAS University Edition (SAS Institute, Cary, NC); all inferential analyses used a two-tailed significance cutoff of 0.05 . We converted participants' quiz responses to a 20-point objective knowledge score based on the number of items answered correctly and calculated the percent correct. We performed multiple linear regression modeling for objective knowledge using age, sex, education level, primary ethnicity, and personal history of glaucoma as covariates. We performed logistic regression modeling for basic glaucoma awareness, good or better self-rated glaucoma 
knowledge, and good or better self-rated ability to use eye drops utilizing the same covariates.

\section{RESULTS}

Of 298 participants, $145(48.7 \%)$ were female, and the average age was $44.9 \pm 17.2$ years. One hundred three $(103,34.6 \%)$ were primarily of Amhara ethnicity, 89 (29.9\%) were of Oromo ethnicity, and $52(17.4 \%)$ were of Gurage ethnicity. The remaining 54 (18.1\%) were of mixed ethnicity. A majority of participants (167; $56.0 \%$ ) had primary school or less than primary school education. The demographic data are summarized in Table 1.

One hundred thirty-one $(131 ; 44.0 \%$ of the overall sample) participants reported previously hearing about glaucoma. In the logistic regression model for basic glaucoma awareness (Table 2), secondary school or greater education level was independently associated with increased awareness of glaucoma $(\mathrm{OR}=4.35$ [95\% CI 2.53-7.48], $p<0.001)$. Older age was also associated with a slightly increased awareness of glaucoma $\quad(\mathrm{OR}=1.02 \quad[95 \% \quad \mathrm{CI}$ 1.01-1.04], $p=0.01)$. Sex, primary ethnicity, and residence did not demonstrate a significant association with increased glaucoma awareness, though there was a slight trend of increased glaucoma awareness among participants from Addis Ababa.

Of the 131 (44.0\% of the overall sample) participants who had a basic awareness of glaucoma, 30 (23\%; 10\% of the overall sample) said they had glaucoma; 57 (43.5\%; 19\% of the overall sample) stated they had learned about glaucoma from television, the radio, or media other than the internet; $28(21.4 \% ; 9.4 \%$ of the overall sample) indicated that they had learned about glaucoma via direct education by a

Table 1 Demographic characteristics for 298 participants, 131 with and 167 without basic awareness of glaucoma

\begin{tabular}{|c|c|c|c|c|}
\hline Characteristic & $\begin{array}{l}\text { All participants } \\
(n=298)\end{array}$ & $\begin{array}{l}\text { Aware } \\
(n=131)\end{array}$ & $\begin{array}{l}\text { Not aware } \\
(n=167)\end{array}$ & $p$ \\
\hline Age (years $\pm S D$ ) & $44.9 \pm 17.2$ & $46.2 \pm 15.3$ & $43.9 \pm 18.5$ & $0.25^{\mathrm{a}}$ \\
\hline Sex & & & & $0.38^{\mathrm{b}}$ \\
\hline Female & $145(48.7 \%)$ & $60(45.8 \%)$ & $85(50.9 \%)$ & \\
\hline Male & $153(51.3 \%)$ & $71(54.2 \%)$ & $82(49.1 \%)$ & \\
\hline Primary ethnicity & & & & $0.53^{\mathrm{b}}$ \\
\hline Amhara & $103(34.6 \%)$ & $49(37.4 \%)$ & $54(32.3 \%)$ & \\
\hline Oromo & 89 (29.9\%) & $34(26.0 \%)$ & $55(32.9 \%)$ & \\
\hline Gurage & $52(17.4 \%)$ & $22(16.8 \%)$ & $30(18.0 \%)$ & \\
\hline Mixed or other & $54(18.1 \%)$ & $26(19.8 \%)$ & $28(16.8 \%)$ & \\
\hline Education level & & & & $<0.001^{\mathrm{b}}$ \\
\hline$\leq$ Primary & $167(56.0 \%)$ & $52(39.7 \%)$ & $115(68.9 \%)$ & \\
\hline$\geq$ Secondary & $131(44.0 \%)$ & $79(60.3 \%)$ & $52(31.1 \%)$ & \\
\hline Residence & & & & $0.28^{\mathrm{b}}$ \\
\hline Addis Ababa & $197(66.1 \%)$ & $91(69.5 \%)$ & $106(63.5 \%)$ & \\
\hline Other & $101(33.9 \%)$ & $40(30.5 \%)$ & $61(36.5 \%)$ & \\
\hline
\end{tabular}

${ }^{a}$ By independent-samples $t$-test assuming unequal variances

b By chi-square test of independence 
Table 2 Multivariable logistic regression analysis of basic glaucoma awareness among 298 participants

\begin{tabular}{|c|c|c|c|c|}
\hline \multirow[t]{2}{*}{ Variable } & \multicolumn{2}{|c|}{ Awareness of glaucoma } & \multirow[t]{2}{*}{ OR $(95 \% \mathrm{CI})$} & \multirow[t]{2}{*}{$p$} \\
\hline & No./total & $\%(95 \% \mathrm{CI})$ & & \\
\hline Age (per 1 year increase) & - & - & $1.02(1.01-1.04)$ & 0.01 \\
\hline Sex & & & & 0.45 \\
\hline Female & $60 / 145$ & $41.4(33.4-49.4)$ & 1 [reference] & \\
\hline Male & $71 / 153$ & $46.4(38.5-54.3)$ & $1.22(0.73-2.04)$ & \\
\hline \multicolumn{5}{|l|}{ Primary ethnicity } \\
\hline Amhara & $49 / 103$ & $47.6(38.0-57.2)$ & 1 [reference] & \\
\hline Oromo & $34 / 89$ & $38.2(28.1-48.3)$ & $0.72(0.37-1.40)$ & 0.33 \\
\hline Gurage & $22 / 52$ & $42.3(28.9-55.7)$ & $1.23(0.59-2.57)$ & 0.58 \\
\hline Mixed or other & $26 / 54$ & $48.1(34.8-61.4)$ & $1.46(0.71-2.99)$ & 0.30 \\
\hline Education level & & & & $<0.001$ \\
\hline$\leq$ Primary & $52 / 167$ & $31.1(24.1-38.1)$ & 1 [reference] & \\
\hline$>$ Primary & $79 / 131$ & $60.3(51.9-68.8)$ & $4.35(2.53-7.48)$ & \\
\hline Residence & & & & 0.74 \\
\hline Addis Ababa & $91 / 197$ & $46.2(39.2-53.2)$ & 1 [reference] & \\
\hline Other & $40 / 101$ & $39.6(30.1-49.1)$ & $0.91(0.51-1.62)$ & \\
\hline
\end{tabular}

healthcare provider. Only 37/131 (28.2\%) selfrated their knowledge of glaucoma as good or very good, but 100/131 (76.3\%) self-rated their ability to use eye drops as good or very good. Receptiveness to glaucoma treatment was high, with $126 / 131(96.2 \%)$ stating a willingness to use eye drops to treat glaucoma and 130/131 (99.2\%) indicating a willingness to undergo surgery for glaucoma if it was recommended by an ophthalmologist.

In the logistic regression for self-rated knowledge of glaucoma (Table 3), personal history of glaucoma was independently associated with good or very good self-rated glaucoma knowledge $(\mathrm{OR}=3.75$ [95\% CI 1.29-10.92], $p=0.02$ ), but none of the other covariates were independently associated with self-rated drop use ability. In the logistic regression for ability to use eyedrops (Table 4), no covariates were independently associated with good or very good self-rated ability to use eyedrops.
The mean objective knowledge score was $11.8 \pm 2.2(59.0 \pm 11.0 \%$ correct $)$ out of 20 . Regarding specific quiz items, 124/131 (94.7\%) knew that glaucoma was treatable, 103/131 $(78.6 \%)$ knew that glaucoma is often asymptomatic in its early stages, 95/131 (72.5\%) knew that glaucoma causes permanent vision loss, $62 / 131(47.3 \%)$ knew that glaucoma was related to elevated IOP, and 33/131 (25.2\%) knew that glaucoma resulted from damage to the optic nerve. In the linear regression for objective knowledge score (Table 5), secondary school or greater education level was independently associated with a higher knowledge score $(p=0.03)$, but age, sex, primary ethnicity, and personal history of glaucoma were not.

\section{DISCUSSION}

Through a cross-sectional study, we sought to evaluate awareness and understanding of 
Table 3 Multivariable logistic regression analysis of self-rated good or very good knowledge of glaucoma among 131 participants with basic awareness of glaucoma

\begin{tabular}{|c|c|c|c|c|}
\hline \multirow[t]{2}{*}{ Variable } & \multicolumn{2}{|c|}{$\geq$ Good self-rated knowledge } & \multirow[t]{2}{*}{ OR $(95 \% \mathrm{CI})$} & \multirow[t]{2}{*}{$p$} \\
\hline & No./total & $\%(95 \% \mathrm{CI})$ & & \\
\hline Age (per 1 year increase) & - & - & $1.00(0.97-1.03)$ & 0.93 \\
\hline Sex & & & & 0.74 \\
\hline Female & $14 / 60$ & $23.3(12.6-34.0)$ & 1 [reference] & \\
\hline Male & $23 / 71$ & $32.4(21.5-43.3)$ & $1.17(0.47-2.87)$ & \\
\hline \multicolumn{5}{|l|}{ Primary ethnicity } \\
\hline Amhara & $11 / 49$ & $22.4(10.7-34.1)$ & 1 [reference] & \\
\hline Oromo & $11 / 34$ & $32.4(16.7-48.1)$ & $1.51(0.50-4.57)$ & 0.47 \\
\hline Gurage & $6 / 22$ & $27.3(8.7-45.9)$ & $1.26(0.34-4.62)$ & 0.73 \\
\hline Mixed or other & $9 / 26$ & $34.6(16.3-52.9)$ & $2.17(0.70-6.75)$ & 0.18 \\
\hline Education level & & & & 0.12 \\
\hline$<$ Secondary & $11 / 52$ & $21.2(10.1-32.3)$ & 1 [reference] & \\
\hline$\geq$ Secondary & $26 / 79$ & $32.9(22.5-43.3)$ & $2.07(0.82-5.19)$ & \\
\hline Residence & & & & 0.63 \\
\hline Addis Ababa & $26 / 91$ & $28.6(19.3-37.9)$ & 1 [reference] & \\
\hline Other & $11 / 40$ & $27.5(13.7-41.3)$ & $0.79(0.30-2.09)$ & \\
\hline History of glaucoma & & & & 0.02 \\
\hline No & $22 / 101$ & $21.8(13.8-29.9)$ & 1 [reference] & \\
\hline Yes & $15 / 30$ & $50.0(32.1-67.9)$ & $3.75(1.29-10.92)$ & \\
\hline
\end{tabular}

glaucoma among adults in an urban clinical setting of Addis Ababa, Ethiopia. Our study found that the prevalence of glaucoma awareness was $44.0 \%$. This rate is slightly higher than other published studies from Ethiopia. In a 2017 study performed in Gondar Town, Northwest Ethiopia, the prevalence of glaucoma awareness was $35.1 \%$, while a 2013 study from Addis Ababa determined the prevalence of glaucoma awareness was $28.4 \%[8,9]$. This variance between studies could represent substantive increases in glaucoma awareness over time but could also reflect differences in methodology and/or clinical setting. Interestingly, a third study performed in southwestern Ethiopia found that only $2.4 \%$ of participants were aware of glaucoma [10]. However, that particular study defined awareness as knowing something about glaucoma beyond having simply heard of the condition and was conducted in a rural environment where access to educational material might not be as readily available. Regardless, these investigations all demonstrate that awareness of glaucoma is well below optimal levels in Ethiopia.

While it is difficult to directly compare levels of awareness because of methodologic differences between studies, the prevalence of glaucoma awareness noted in the current study is similar to that measured in many other countries. A study of non-clinical, administrative staff at a Nigerian hospital found that just 
Table 4 Multivariable logistic regression analysis of self-rated good or very good ability to use eye drops among 131 participants with basic awareness of glaucoma

\begin{tabular}{|c|c|c|c|c|}
\hline \multirow[t]{2}{*}{ Variable } & \multicolumn{2}{|c|}{$\geq$ Good self-rated drop ability } & \multirow[t]{2}{*}{ OR $(95 \% \mathrm{CI})$} & \multirow[t]{2}{*}{$p$} \\
\hline & No./total & $\%(95 \% \mathrm{CI})$ & & \\
\hline Age (per 1 year increase) & - & - & $1.00(0.97-1.03)$ & 0.96 \\
\hline Sex & & & & 0.18 \\
\hline Female & $42 / 60$ & $70.0(58.4-81.6)$ & 1 [reference] & \\
\hline Male & $58 / 71$ & $82.0(73.1-90.9)$ & $1.86(0.74-4.64)$ & \\
\hline \multicolumn{5}{|l|}{ Primary ethnicity } \\
\hline Amhara & $40 / 49$ & $81.6(70.8-92.5)$ & 1 [reference] & \\
\hline Oromo & $28 / 34$ & $82.4(69.6-95.2)$ & $0.82(0.23-2.87)$ & 0.75 \\
\hline Gurage & $14 / 22$ & $63.6(43.5-83.7)$ & $0.35(0.10-1.21)$ & 0.10 \\
\hline Mixed or other & $18 / 26$ & $69.2(51.5-86.9)$ & $0.49(0.16-1.54)$ & 0.22 \\
\hline Education level & $38 / 52$ & $73.1(61.1-85.2)$ & 1 [reference] & \\
\hline$<$ Secondary & $62 / 79$ & $78.5(69.4-87.6)$ & $1.05(0.42-2.60)$ & \\
\hline$\geq$ Secondary & & & & 0.92 \\
\hline Residence & & & & 0.97 \\
\hline Addis Ababa & $68 / 91$ & $74.7(65.8-83.6)$ & 1 [reference] & \\
\hline Other & $32 / 40$ & $80.0(67.6-92.4)$ & $1.02(0.36-2.86)$ & \\
\hline History of glaucoma & & & & 0.74 \\
\hline No & $76 / 101$ & $75.2(66.8-83.6)$ & 1 [reference] & \\
\hline Yes & $24 / 30$ & $80.0(65.7-94.3)$ & $1.22(0.38-3.95)$ & \\
\hline
\end{tabular}

29.2\% had heard of glaucoma [11]. Other recent studies from urban settings in India, Pakistan, and Iran found prevalence rates of glaucoma awareness of $45 \%, 48.7 \%$, and $46.6 \%$, respectively [12-14]. Given the relatively higher contribution of glaucoma to overall blindness in east SSA countries (11.7\%) relative to South Asian (5.81\%) or Middle Eastern countries (6.89\%), the comparable awareness levels found in Ethiopia suggest a disconnect between glaucoma awareness and willingness to undergo treatment.

Our study suggests that increasing age and having at least some secondary school education are independently associated with awareness of glaucoma. This is consistent with the findings in the study performed in Gondar [8]. In all three of the aforementioned awareness studies performed in Ethiopia, a significant association between level of education and glaucoma awareness was found [8-10]. This is consistent with studies from other countries as well [15-17]. Our current study, however, did not find any association between awareness of glaucoma and sex, primary ethnicity, or residence in Addis Ababa. In the present study, $28.2 \%$ of participants rated their knowledge of glaucoma as good or very good. Again, it is challenging to make direct comparisons, especially since this study assessed self-reported glaucoma knowledge while other studies utilized differing objective score measures, but this 
Table 5 Multivariable linear regression analysis of objective glaucoma knowledge score among 131 participants with basic awareness of glaucoma

\begin{tabular}{|c|c|c|c|}
\hline \multirow[t]{2}{*}{ Variable } & \multicolumn{2}{|c|}{ Objective glaucoma knowledge score } & \multirow[t]{2}{*}{$p$} \\
\hline & Coefficient & SE & \\
\hline Intercept & 10.52 & 0.83 & $<0.0001$ \\
\hline Age (per 1 year increase) & 0.004 & 0.01 & 0.77 \\
\hline Sex & & & 0.59 \\
\hline Female & $0^{\mathrm{a}}$ & $0^{\mathrm{a}}$ & \\
\hline Male & 0.22 & 0.41 & \\
\hline \multicolumn{4}{|l|}{ Primary ethnicity } \\
\hline Amhara & $0^{\mathrm{a}}$ & $0^{a}$ & \\
\hline Oromo & 0.49 & 0.52 & 0.35 \\
\hline Gurage & 0.23 & 0.58 & 0.70 \\
\hline Mixed or other & 0.48 & 0.53 & 0.36 \\
\hline Education level & & & 0.03 \\
\hline$<$ Secondary & $0^{\mathrm{a}}$ & $0^{\mathrm{a}}$ & \\
\hline$\geq$ Secondary & 0.87 & 0.41 & \\
\hline Residence & & & 0.87 \\
\hline Addis Ababa & $0^{\mathrm{a}}$ & $0^{\mathrm{a}}$ & \\
\hline Other & -0.07 & 0.45 & \\
\hline History of glaucoma & & & 0.08 \\
\hline No & $0^{\mathrm{a}}$ & $0^{\mathrm{a}}$ & \\
\hline Yes & 0.92 & 0.52 & \\
\hline
\end{tabular}

${ }^{a}$ This parameter is set to zero because it is the reference

finding is similar to other studies in Ethiopia and in other countries.

In a recent study of adults in Gish Abay Town, Northwest Ethiopia, $16.8 \%$ of adults were found to have a good knowledge of glaucoma, as defined by a score $>50 \%$ on an objective quiz [18]. In another study from Addis Ababa, good glaucoma knowledge, defined as an ability to describe glaucoma and one risk factor and treatment, was found in just $12.1 \%$ of participants [9]. The average score on the objective knowledge quiz used in the current study was $59 \%$, which would suggest a much better knowledge of glaucoma among participants in our sample compared with these other studies in Ethiopia. However, our study was conducted in a clinical setting, and anyone who had not heard of glaucoma was not given the quiz. Thus, while our results might suggest an improvement in glaucoma understanding, they must be interpreted in context, and further investigation is warranted.

Studies from other African countries have found varying rates of glaucoma knowledge. A study in Nigeria found a prevalence of good knowledge of glaucoma, as defined by a score $>$ $50 \%$ on a basic glaucoma knowledge test, of just $6.7 \%$ in a rural community [19]. A study from 
Ghana found that just $27 \%$ of glaucoma patients in an eye clinic had accurate knowledge of the disease [20]. Our study found that a personal diagnosis of glaucoma was associated with self-rated good or very good knowledge of glaucoma. Since patients who have been diagnosed with glaucoma have undergone an eye examination in the past, this finding is consistent with other studies that have shown that a history of previous eye examinations is correlated with knowledge of glaucoma $[8,18]$. We also found that a higher education level was associated with an increased objective knowledge of glaucoma, which is a finding consistent with other studies $[8,12,16,18]$.

It should be noted that our linear regression model suggests that while significant, the effect of secondary education is relatively small with regard to increased objective knowledge of glaucoma, as the coefficient of 0.87 suggests a $<$ 1-point improvement in score with at least a secondary education. This seemingly small effect can be explained by the fact that individuals who were not aware of glaucoma were not given the objective knowledge quiz. Of those individuals who did not have awareness of glaucoma, a much larger percentage had only a primary school education than those who had heard of glaucoma (68.9\% vs. $39.7 \%)$. However, this dynamic is not reflected in the linear regression model, which therefore suggests that the effect of education is likely larger than reported. Therefore, this result suggests that regional and national efforts to advance education could have a direct impact on healthrelated behaviors. Public awareness campaigns and clinically based patient education may be particularly beneficial in environments with less access to higher education and lower literacy rates.

This study did not find any covariates that were associated with a self-rated good or very good ability to use eyedrops. Further investigation is needed to better identify those who will benefit the most from eyedrop instillation teaching. Other studies have been performed to better understand medication adherence patterns among glaucoma patients. Factors such as higher education level, younger age, a higher frequency of follow-up visits, milder disease stage, and a financial ability to pay for medications have been associated with better adherence in Ethiopian populations [21-23]. While our study found a relatively high proportion of individuals who had confidence in their ability to administer eye drops, these results are limited by the fact that only those individuals who had heard of glaucoma were asked to rate their confidence. Furthermore, there was a significant discrepancy between the proportion of participants who felt they had a good or very good knowledge of glaucoma $(28.2 \%)$ and the proportion of participants who expressed confidence in instilling eyedrops (76.3\%). All of this underscores the importance of teaching patients about proper eye drop instillation, especially since multiple studies have established the connection between eye drop administration, patient self-efficacy, and adherence to treatment [24-26].

Any survey study is subject to limitations. The current study was performed in a tertiary medical center where people have access to medical care and are likely more knowledgeable about medicine in general. As such, the participants may have been biased towards an increased awareness and knowledge of glaucoma relative to other communities, especially those from rural areas where healthcare is less accessible. Furthermore, it is possible that interview bias affected responses, though the interpreters utilized in the study were trained optometrists and made efforts to reduce influencing participant responses.

The primary findings of this study-an overall low prevalence of glaucoma awareness, an association between completed education level and both awareness and knowledge of glaucoma, high patient confidence in the ability to self-administer eye drops, and a remarkably high level of patient willingness to undergo medical or surgical treatment for glaucomademonstrate that there is a significant gap in Ethiopia between glaucoma awareness and acceptance of treatment. Since populationbased advances in general education are likely to take time, public health awareness campaigns and provider-patient educational efforts are likely to achieve a more immediate impact. Additionally, therapeutic treatments that 
effectively achieve lower IOP while requiring less patient adherence and follow-up, such as selective laser trabeculoplasty, could play an increasing role in populations with decreased access to care or glaucoma medications $[27,28]$. Patients' willingness to receive treatment in our study suggests that increasing awareness among those at highest risk of developing glaucoma (age $>40$ years, positive family history) is likely to reduce the disease burden and its associated personal and public costs.

\section{CONCLUSIONS}

In this clinic-based, cross-sectional study, awareness and knowledge of glaucoma within an Ethiopian population were generally poor. Awareness and knowledge of glaucoma were both associated with higher levels of education. This suggests that educational interventions at the public health and provider-patient levels may potentially improve awareness and understanding of glaucoma in a population that is amenable to treatment.

\section{ACKNOWLEDGEMENTS}

We thank the participants of the study who generously gave of their time for the advancement of knowledge.

Funding. This study was funded by an unrestricted grant from Research to Prevent Blindness (New York, NY, USA). No funding or sponsorship was received for the publication of this article.

Authorship. All named authors meet the International Committee of Medical Journal Editors (ICMJE) criteria for authorship for this article, take responsibility for the integrity of the work as a whole, and have given their approval for this version to be published.

Disclosures. Curtis J. Heisel, Cherinet Markos, Philip S. Garza, Girum W. Gessesse, Christine C. Nelson, Lemlem Tamrat, Rebhi
Abuzaitoun, and Scott D. Lawrence declare that they have no conflict of interest.

Compliance with Ethics Guidelines. This study was approved by both the University of Michigan (HUM00148963) and St. Paul's Millennium Medical College Institutional Review Boards. This study was performed in accordance with the tenets of the Declaration of Helsinki and its later amendments. All subjects provided informed consent to participate in the study.

Data Availability. The datasets generated during and/or analyzed during the current study are available from the corresponding author on reasonable request.

Open Access. This article is licensed under a Creative Commons Attribution-NonCommercial 4.0 International License, which permits any non-commercial use, sharing, adaptation, distribution and reproduction in any medium or format, as long as you give appropriate credit to the original author(s) and the source, provide a link to the Creative Commons licence, and indicate if changes were made. The images or other third party material in this article are included in the article's Creative Commons licence, unless indicated otherwise in a credit line to the material. If material is not included in the article's Creative Commons licence and your intended use is not permitted by statutory regulation or exceeds the permitted use, you will need to obtain permission directly from the copyright holder. To view a copy of this licence, visit http://creativecommons.org/licenses/bync/4.0/.

\section{REFERENCES}

1. Quigley HA, Broman AT. The number of people with glaucoma worldwide in 2010 and 2020. Br J Ophthalmol. 2006;90:262-7.

2. Tielsch JM, Sommer A, Katz J, Royall RM, Quigley HA, Javitt J. Racial variations in the prevalence of primary open-angle glaucoma: the Baltimore eye survey. JAMA. 1991;266:369-74. 
3. Leske M, Connell A, Schachat A, Hyman L. The Barbados eye study: prevalence of open angle glaucoma. Arch Ophthalmol. 1994;112:821-9.

4. Mitchell P, Smith W, Attebo K, Healey PR. Prevalence of open-angle glaucoma in Australia: the Blue Mountains Eye Study. Ophthalmology. 1996;103: 1661-9.

5. Flaxman SR, Bourn RRA, Resnikoff S, et al. Global causes of blindness and distance vision impairment 1990-2020: a systematic review and meta-analysis. Lancet Glob Health. 2017;5:e1221-34.

6. Cherinet FM, Tekalign ST, Anbesse DH, Bizuneh ZY. Prevalence and associated factors of low vision and blindness among patients attending St. Paul's Hospital Millennium Medical College, Addis Ababa Ethiopia. BMC Ophthalmol. 2018;18:232.

7. Giorgis AT. Raising public awareness of glaucoma in Ethiopia. Community Eye Health. 2012;25:46.

8. Alemu DS, Gudeta AD, Gebreselassie KL. Awareness and knowledge of glaucoma and associated factors among adults: a cross sectional study in Gondar Town, Northwest Ethiopia. BMC Ophthalmol. 2017;17:154.

9. Hiwot D, Abeba TG. Glaucoma awareness among ophthalmic patients at Menelik II Hospital, Addis Ababa, Ethiopia. Ethiop J Health Dev. 2013;27: 230-4.

10. Tenkir A, Solomon B, Deribew A. Glaucoma awareness among people attending ophthalmic outreach services in Southwestern Ethiopia. BMC Ophthalmol. 2010;10:17.

11. Komolafe OO, Omolase CO, Bekibele CO, Ogunleye OA, Komolafe OA, Omotayo FO. Awareness and knowledge of glaucoma among workers in a Nigerian tertiary health care institution. Middle East Afr J Ophthalmol. 2013;20:163-7.

12. Krishnan VM, Baba DD, Kumar DR, Natarajan DS. Prevalence of awareness and knowledge of glaucoma in urban Puducherry. Sch J Appl Med Sci. 2015;3:2561-7.

13. Inayat $\mathrm{N}$, Moin $\mathrm{M}$, Manzoor A. Awareness of glaucoma in different groups of urban population. Pak J Ophthalmol. 2014;30:142-6.

14. Katibeh M, Ziaei H, Panah E, et al. Knowledge and awareness of age related eye diseases: a populationbased survey. J Ophthalmic Vis Res. 2014;9:223-31.

15. Mbadugha CA, Onakoya AO. The awareness, perceptions and experiences of primary open angle glaucoma patients in Lagos Nigeria. Sci Rep. 2014;4: 7585 .
16. Rewri P, Kakkar M. Awareness, knowledge, and practice: a survey of glaucoma in north Indian rural residents. Indian J Ophthalmol. 2014;62:482-6.

17. Sathyamangalam RV, Paul PG, George R, et al. Determinants of glaucoma awareness and knowledge in urban Chennai. Indian J Ophthalmol. 2009;57:355-60.

18. Yenegeta Z, Tsega A, Addis Y, Admass F. Knowledge of glaucoma and associated factors among adults in Gish Abay town, Northwest Ethiopia. BMC Ophthalmol. 2020;20:8.

19. Ogbonnaya CE, Ogbonnaya LU, Okoye O, KizorAkaraiwe NN. Glaucoma awareness and knowledge, and attitude to screening, in a rural community in Ebonyi State, Nigeria. Open J Ophthalmol. 2016;6: 119-27.

20. Nkum G, Lartey S, Frimpong C, Micah F, Nkum B. Awareness and knowledge of glaucoma among adult patients at the eye clinic of a teaching hospital. Ghana Med J. 2015;49:195-9.

21. Anbesse DH, Yibekal BT, Assefa NL. Adherence to topical glaucoma medications and associated factors in Gondar University Hospital Tertiary Eye Care Center, northwest Ethiopia. Eur J Ophthalmol. 2019;29:189-95.

22. Tamrat L, Gessesse GW, Gelaw Y. Adherence to topical glaucoma medications in Ethiopian patients. Middle East Afr J Ophthalmol. 2015;22: 59-63.

23. Mehari T, Giorgis AT, Shibeshi W. Level of adherence to ocular hypotensive agents and its determinant factors among glaucoma patients in Menelik II Referral Hospital, Ethiopia. BMC Ophthalmol. 2016;16:131.

24. Sayner R, Carpenter DM, Robin AL, et al. How glaucoma patient characteristics, self-efficacy and patient-provider communication are associated with eye drop technique. Int $\mathrm{J}$ Pharm Pract. 2016;24:78-85.

25. Sleath B, Blalock SJ, Carpenter DM, et al. Provider education about glaucoma and glaucoma medications during videotaped medical visits. J Ophthalmol. 2014;2014:238939.

26. Sleath B, Blalock SJ, Carpenter DM, et al. Ophthalmologist-patient communication, self-efficacy, and glaucoma medication adherence. Ophthalmology. 2015;122:748-54.

27. Realini T, Shillingford-Ricketts H, Burt D, Balasubramani GK. West Indies Glaucoma Laser Study (WIGLS) 1. 12-month efficacy of selective laser 
trabeculoplasty in Afro-Caribbeans with glaucoma. Am J Ophthalmol. 2017;184:28-33.

28. Gazzard G, Konstantakopoulou E, Garway-Heath D, et al. Selective laser trabeculoplasty versus eye drops for first-line treatment of ocular hypertension and glaucoma (LiGHT): a multicentre randomized controlled trial. Lancet. 2019;393:1505-16. 